\title{
Future Housing Identities: Designing in Line with the Contemporary Sustainable Urban Lifestyle
}

\author{
Ana Nikezić, Jelena Ristić Trajković (D) and Aleksandra Milovanović *iD \\ Faculty of Architecture, University of Belgrade, 11000 Belgrade, Serbia; ana.nikezic@arh.bg.ac.rs (A.N.); \\ jelena.ristic@arh.bg.ac.rs (J.R.T.) \\ * Correspondence: alekmil@arh.bg.ac.rs
}

Citation: Nikezić, A.; Ristić Trajković, J.; Milovanović, A. Future Housing Identities: Designing in Line with the Contemporary Sustainable Urban Lifestyle. Buildings 2021, 11, 18 https://doi.org/10.3390/buildings 11010018

Received: 19 November 2020 Accepted: 24 December 2020 Published: 4 January 2021

Publisher's Note: MDPI stays neutral with regard to jurisdictional clai$\mathrm{ms}$ in published maps and institutional affiliations.

Copyright: (C) 2021 by the authors. Licensee MDPI, Basel, Switzerland. This article is an open access article distributed under the terms and conditions of the Creative Commons Attribution (CC BY) license (https:// creativecommons.org/licenses/by/ $4.0 /)$.

\begin{abstract}
Over the past decade, urban housing typologies have evolved from being a feature of modern life to an essential postmodern issue, questioning future housing identities. One of the ways in which architecture can become engaged in this ever-changing process of urban regeneration is to challenge the inherited traditional housing typologies with the newly recognized values of contemporary lifestyle. This paper presents research and design aimed at exploring contemporary sustainable urban lifestyles as a resource for positioning housing structures as cultural urban infrastructure. The main focus of this study is design principles and strategies for generating future housing identities in accordance with sustainable urban development and sustainability of life in urban areas. It is about finding housing conceptual models for an interaction between housing and identity as a response to the impact of increased cities, changed lifestyles in contemporary cities and the requirements for the preservation of the city image and the public space within the housing areas in the city center. The main goal of this study is to understand whether and how an architectural design can preserve a sustainability of life within the city center and become a valuable agent of place identity in the process of urban regeneration. The paper indicates that the contemporary development of society requires a new architectural paradigm, in which lifestyle and architecture create a unique elastic open-ended system with the ability to adapt and change over time and throughout the place.
\end{abstract}

Keywords: housing; identity; sustainable urban and architectural design; sustainable urban regeneration; public space

\section{Introduction}

In the first decade of the 21st century, urbanization led to $50 \%$ of the world's population living in cities with a trend of further growth. This makes the problems of urban planning and organization an important topic of development agendas at the European and global level. One of the leading goals and transformative steps within the 2030 Agenda for Sustainable Development, as a global action plan for people, planet and prosperity, refers to "making cities and human settlements inclusive, safe, resilient and sustainable" [1]. The connection between architecture and sustainability is unequivocally important bearing in mind that one of the basic tasks of an architectural discipline as an applied spatial science is to think, design and manage the built environment in a way that will satisfy the needs of future humanity. The emergence period of sustainable and environmental movements in architecture largely coincides with the emergence of environmental-behavioral studies in response to the neglect of local context characteristics, cultural conditions and user-environment relations in a specific context [2]. Accordingly, the concept of sustainability is recognized as an influential contemporary tool for the delivery of environmental sensitivity which implies integration of social factors, culture and technology with architecture [3]. In that order, the continuous re-examination of current approaches to the research, evaluation, planning and design of the sustainable built environment and land use has become a necessary task for researchers, educators, policy makers and practitioners in the field of architecture and urbanism. 
City centers are places with a significant cultural heritage and specific morphology, ambience and urban identity [4]. Intensive urban development of these areas very often leads to the loss of individuality and distinctiveness of the place. Protecting and improving local identity and culture has numerous benefits, such as enhancing the social cohesion and well-being of the city's inhabitants, preserving the city's image, creating peoplecentered, livable cities, providing good-quality public open spaces, etc. Bearing in mind the complexity of activities and various relations within dwellings in the city center, housing plays a very important role for the quality of the experience of these areas and in achieving ecological and cultural sensitivity, as well as the sustainability of urban life. Such perspective engages people and their intimate places in a new way, where privacy, technology, mobility, working conditions and cultural diversity acquire new meanings and positions.

Urban regeneration is a process that involves the spatial and cultural transformation of inherited structures of the city in which all the vital functions of the city communities are maintained without compromising the basis on which they are based, both in the domain of community institutions, means of production, infrastructure, and natural and human resources, as well as in the character and identity of the inherited urban fabric [5]. In this complex urban process, housing has acquired completely new dimensions of perception aimed at understanding the everyday life of users and their mapping onto lifestyles in order to provide a modern, healthy and quality life while preserving the character and identity of the inherited urban structure. Observed from the point of view of housing, urban regeneration enables the revival of the inherited urban structure of the city center, through attracting human resources interested in the urban way of life and through the inclusion of the inherited community in modern life. In this sense, contemporary studies recognize the importance of the concept of inclusive cities and the issue of diversity that characterizes urban spaces as planning strategies for achieving the right to a city [6]. Accordingly, the basic determinant and guiding principle of the regeneration of the city center is the concept of sustainability in line with a competitive style of urban life. This approach is difficult because the way of life is not constant, but changes in accordance with the dynamics of family structure, social organization, economic prosperity or decline, technological changes, environmental problems, demographic trends, political conflicts, etc. The goal of transforming the collective housing in the city center is to achieve competitive urban life through the successful integration of residential and public urban space, the creation of new types of facilities, balance of technological and cultural values of the city. Therefore, the future user should have a central role in the process of transformation of collective housing in the city center by engaging in a gendered perspective and understanding the different cultural and geographical origins of users, as well as their particular capacities and needs. The lifestyle of the inhabitants indirectly affects encouraging sensibility and suitability of the urban structure for certain user profiles. Although the residents who perceive the city center as a living space have diverse backgrounds, as well as cultural, professional and social aspirations, all strive for inclusion in the inherited structure of the modern way of life and the increase of urbanity.

One of the most significant challenges in sustainable urban regeneration and in comprehensive city development is how to incorporate place identity, urban sustainability and globalization $[7,8]$. According to Sepe [8], a place's sustainability depends on factors that support its livability, quality and identity. In addition, cultural globalization in recent years has raised a concern about the loss of individuality and distinctiveness from one place to another. This is the reason why place identity has become an essential issue in city planning and design, and an essential concept in the process of sustainable development [7]. Building in a sustainable way implies the preservation of the characteristics that make every place and every city a unique, cultural environment [9].

During the process of city regeneration and redevelopment, considerations in a local context are not only concerned with the city as a place, but also with the people that live in and create the built environment. In line with this concern, a significant number of studies 
in recent years have paid attention to the man-made environment as well as people's reading of the city [10]. As stated by Cesare [11], over the last decade the emerging culture of sustainability has encouraged planning procedures that are more and more sensitive to the surroundings; such a principle is strongly supported by anthropology, according to which the recognition of place identity is the prerequisite for every action.

It is not an easy task to look for a theory that advocates the influence housing has, and could have, on identity. Recognizing the gap in previous research, which mostly relies on environment and behavior transactional theories, primarily the social identity theorywidely accepted, but very general-this research is directed towards the affirmation of housing identity and improvement of everyday life by discovering new possibilities in the relationship between lifestyle and people through architecture. Beyond the inherent approaches of housing identities, research contends the question of how the contemporary sustainable urban lifestyle could be examined with respect to design strategies essential to reach a holistic view of a place. Accordingly, this paper starts from the premise that future housing identities imply active involvement of people and their environment through architecture, which is adaptive, mobile and transparent in its program, and ephemeral and illusive in its form. Therefore, architecture affects the process of living, thus creating a new culturally progressive urban landscape as part of a future identity.

Since this paper is about urban housing, the major points of departure look upon the fluidity of urban everydayness [12], individuality of urban life [13] and domestication of media technology [14] as lenses through which future urban housing identity is observed. The main objective of this study is to understand whether and how an architectural design can preserve sustainability of life within the city center and become a valuable agent of place identity in the process of urban regeneration. When it comes to designing housing facilities in tune with future urban identities, the main research question is how changes in demographic structure (alteration of family structure) and working habits, together with increasing mobility, global digitalization and the culture of post-Fordism, could be transferred into design principles and used as a pertinent resource for future architecture. In this way, influenced by contemporary behaviors and associations [15,16], urban housing becomes an identity communicator [17] and an urban culture medium [18] in reaching sustainable urban regeneration.

The contribution of this paper to architectural and urban design, as well as urban and typo-morphological studies, can be described in three levels. The first level shows our research on the theoretical background through a literature review, mainly on the meaning of housing, dwelling and place identity as seen from the perspective of sustainable urban development and architectural design and explored through other bordering disciplines, such as environment and behavior transactional studies, and primarily the social identity theory. On the second level, the described theoretical framework was developed through a research design methodology employed within the design-based studio course on multi-family housing at the University of Belgrade-Faculty of Architecture to define principles and strategies in line with contemporary sustainable urban lifestyles. On the third level, based on the design proposals, and through the analysis of the chosen role models, three conceptual scenarios are defined: meta-housing, custom-made habitation and maximal minimum.

Hence, the paper evolves through four sections:

- Theoretical background: discussion on the meaning of housing, dwelling and place identity as seen from the perspective of sustainable urban development and architectural design, but explored through other bordering disciplines;

- Materials and methods: explanation of the research design and case study;

- Findings and discussion: recognition of key values of future housing identities and definition of conceptual models of future housing identities;

- Concluding remarks. 


\section{Theoretical Background: The Phenomenon of Housing Identity}

To develop a theoretical framework that could define the influence of housing on identity and their interrelation, three central research questions were developed to:

- Define a meaningful and conceptual relationship between housing and dwelling in order to explain the interaction between place and people through housing;

- Re-examine place dependence and personal identity;

- Cross the conceptual frameworks of urban housing, place identity and lifestyle to explain the connection between behavior and architecture and recognize paradigmatic frameworks.

In architecture, housing refers to physical structures and buildings intended for people to live in collectively. It also includes any open space that is occupied by the structure. These buildings or structures and open spaces have personal, social and cultural meanings attached to them (different views of home, domestication, everyday routines, family rituals and lifestyles). In this sense, if we want to talk about the interaction between place and people provided by housing and the presented identity which is built from this relationship, we should use the word "dwelling." A dwelling is housing where someone is living and which helps to establish a meaningful relationship between people and the environment [19-22]. The concepts of "housing" or "dwelling," as well as "house" or "home" as complementary in the sphere of individual living, have different meanings attached to them. A distinction between "house" or "housing" merely as a physical structure without meanings ascribed to it, and "home" or "dwelling" as a set of meanings would be artificial. According to Clapham [23], a "house" is not a neutral setting. A house carries meanings that arise out of and in turn influence the use of the physical structure. Housing, as a house, and in particular urban housing, is linked to many other areas of life, creating housing patterns or systems of interaction between structure and program over time and space. In addition, "housing" should not be understood as a static physical construction because it always implies a social dimension, even when the occupiers have no intention of creating a home [23-25]. Meanings that could be associated with, created for, and projected through such structures are of interest to this research. Therefore, housing experienced as a dwelling is a physical manifestation of personality, taste, interests, status, relationship, lifestyle, etc. It can be seen as an attitude toward self-presentation and could serve as an identity communicator. Seen in this way, housing influences both personal and social identity through the association established between the residents, location, and the built environment that facilitates their behavior and social interaction. The described association takes place at several spatial levels: from the wider spatial perspective of the city and city streams, to the gravitational area inside which all morphological, ambient, and behavioral aspects together create the identity of everyday life and the lifestyle of the population.

Personal identity is a human capacity, rooted in language, to know who we are among other people. It is manifested mainly through embodiment, clothing and language [26]. Everyone has a multiple identity that shift between different contexts (work, family, friends, etc.). Identities are shared across limits of privacy and, in this way, space itself becomes a partner in this unique representation. Identification is a basic cognitive mechanism to sort out oneself. It means assigning meanings and providing social interaction involving argument, innovation, communication and negotiation.

Place is a geographical space that has acquired meaning as a result of a person's interaction with space [27]. The meaning of place is constantly being evaluated and redefined in light of social and physical relationships with the place and between people. Thus, we could say that place identity is a manifestation of personal identity through physical environments and objects [28,29]. Breakwell's identity process theory illustrates these mechanisms through four principles described as central to people's identity in Western culture [29]. These principles are: (1) self-esteem as a positive self-evaluation, (2) selfefficiency as a wish to feel in control of oneself and the place around, (3) distinctiveness as a desire to emphasize uniqueness, and (4) continuity as a connection between past and future. Many different manifestations of previously experienced phenomena can be read from 
the attitudes, activities and languages people use. For the purpose of this study we focus more specifically on housing and how identity manifests itself in it. Identity, therefore, (1) manifests the uniqueness of a thing or a person, (2) requires interaction between things and persons, (3) has meaning and experience and (4) is perceptible. It is an evolving and dynamic, rather than stable, concept.

People often read environments as statements about the significance or value of a place and people [30]. In that order, place and people are part of an inclusive entity [31] and that interaction between them is crucial for the creation of the identity people assume for themselves and for others. Gifford [30] emphasizes the interactive quality of the dynamic relationship between people and place, suggesting that this relation goes in both directions - that people seek and create an environment that supports and strengthens their perception. One of the most important aspects of this bond people build with the place are the immediate context and situation [32] in which everyday life takes place. According to Norberg Schultz [33], place as an integral part of existence, refers to the context and situation (i.e., the way in which one understands, connects and harmonizes with the inherited and lived built surroundings), but also the way in which it carries the immaterial cultural connection to it. In reflecting on previous and expecting future lifeworld, a place identity is created [33]. The two previously identified notions, namely (1) housing as a dwelling and (2) place identity as the bond between people and place, overlap and intersect in housing. To interpret oneself through housing is a search for future housing identities, and it runs across lifestyles [23]. We are talking about an integrated set of practices (routines, habits and rituals) that an individual embraces because they give a material form to a narrative of self-identity [13]. Expression of lifestyle is an identity statement [34] and hence, in our case, housing could be able to capture the urban narrative through architecture in creating housing identity. This study considers lifestyle as a construct which is more directly linked to personal and urban identity. The authors consider everyday life as daily routines, the ways in which people usually think, act and feel on a daily basis, while lifestyle implies beliefs, interests, opinions and behaviors of an individual, group or culture. In this way, architecture becomes both an agent that transmits messages and an agency, giving information with its structure (i.e., volume, articulation, exterior and interior, transparency, etc.). Thus, the connection between behavior and architecture is created through housing identity.

\section{Materials and Methods}

\subsection{Research Design}

Since the discipline of architecture and, in particular, the field of architectural design, are platforms through which the present research operates, the suggested methodology combines research by design in the first phase and qualitative data analysis as an argumentative systematization in the second phase. In line with this, the first phase is focused on exploring models of future housing identities, while the second is focused on explaining models and speculating on future housing scenarios in line with contemporary urban everyday life and sustainability. While the first is speculative and subjective embedded in the local context, the second is objective and mainly universal in defining conceptual principles and scenarios for future housing identities [35].

\subsubsection{First Phase-Designing Future Housing Identities}

This part of the research was conducted in the context of a studio-based environment in which different concepts were explored within a given spatial framework. The research was challenged within the design studio course on multi-family housing at the University of Belgrade-Faculty of Architecture. The course involved 28 students divided into two groups of 14 students, according to the spatial framework, each with its own design proposal. Two-thirds of the students who participated in the design studio were women, which is the average ratio between men and women at the University of Belgrade-Faculty of Architecture (from the beginning to the end of their studies). 
Designing future housing identities was guided by exploring different housing models on the basis of individual and creative interpretation of the context, individual beliefs, values and aspirations [35]. It was resolved in harmony with the theoretical background focusing on fluidity of urban everydayness [12], individuality of urban life [13] and domestication of media technology (i.e., introducing the bond between behavior and architecture into housing models) [14].

The exploratory phase was tested through three different steps and in three different scales:

- Typo-morphological exploration that tests the relation between city and architecture;

- Programming - setting up design perspectives that test the relation between everyday life and architecture;

- Conceptual modeling that tests various spatial articulation and ambient sequence.

\subsubsection{Second Phase-Scenarios of Future Housing Identities}

This part of the research was conducted as a qualitative data analysis based on 28 design proposals resolved and carried out in the first phase. It is comparative by nature as it recognizes, combines, systematizes and synthetizes individual proposals creating a unique and universal agenda for future housing identities.

The explanatory phase was performed through three steps:

- Recognition of key values of future housing models embedded in the majority of proposed designs generated in accordance with design perspectives defined through the conceptual framework;

- Identification of role models and their analysis by pinpointing six out of 28 design proposals and qualitative data analysis based on the recognized values;

- Creation of scenarios for future housing identities carried out through interpretation of the results of the analysis and in line with the proposed conceptual framework.

\subsection{Qualitative Data Analysis}

In architectural or environmental design research, artifacts, buildings and settings are often the "texts" that are the subject of interpretation and reinterpretation [36]. Accordingly, this research starts from an interpretative approach to qualitative data analysis [37]. Human activity and the built environment are seen as "text" - a collection of symbols expressing layers of meanings.

This approach enabled the review of specific situations embedded in the context of Belgrade city center, as well as in contemporary dwelling culture and lifestyle. It allowed for a rich and holistic approach when analyzing data, with a strong potential for revealing the complexity of dwelling and identity issues. Miles and Huberman [37] state that qualitative data are fundamentally well situated for locating the meanings people place on the events, processes and structures of their lives, and also for connecting these meanings to the social world around them. According to the same authors, qualitative data analysis is conducted through data reduction, data display and conclusion drawing/verification; however, this is a continuous iterative enterprise. Issues of data reduction, data display and conclusion drawing/verification follow each other successively but the other two issues are always involved [37]. Analyzed data are primary collected through the process of observation, as well as primary and secondary data sources. Relevant data were chosen according to defined criteria for the analysis as explained in following text.

On the basis of conceptual framework, and in looking for key values regarding relevant data from proposed designs, three important values emerged as the most important aspect of the bond between behavior and architecture.

- On the typo-morphological level-the overlapping of the urban and individual dimensions of life was the most evident. It was based on (a) demographic and family structure change, (b) densification and compaction of neighborhood structure and (c) the recognition of alternative lifestyles (i.e., distinguished personal identity); 
- On the programming level—setting up a new housing perspective through the creation of the characteristics of a specific place that was able to engage diverse communities through (a) flexibility and adaptability, (b) attractiveness, accessibility and openness and (c) integration of living, work, leisure, recreation, education, public health, etc.;

- On the architectural level - articulation and ambient sequences transgressed into a new life-form that was the most apparent as interpreted through (a) domestication of media technology, (b) increased and transformed mobility and (c) changed patterns of everyday life.

We were looking for design solutions in which housing typology (1) is a frame and a platform for a specific-place character able to engage the local community; (2) allows an overlap of the urban and individual dimensions of life and eventually (3) transgresses into a new life form. These new housing models have their own social and ideological meanings, that is, they are integral parts of certain social values, ideologies, aspirations and status symbols. In line with this, the possibility of establishing sustainable identity of housing and integrating it with social identity is re-examined. Given the interdisciplinary nature of the problem of housing, research in this field implies the establishment of cause-and-effect relationships between social changes, housing culture and the spatial and functional structure of a house. Connection between housing and identity can be achieved through: associations that users develop with public or private housing spaces; models of housing structures that help users achieve the desired social interaction; aesthetic and visual elements; redefinition of the morphological structure and housing program, etc. A conceptual framework diagram is shown in Figure 1.

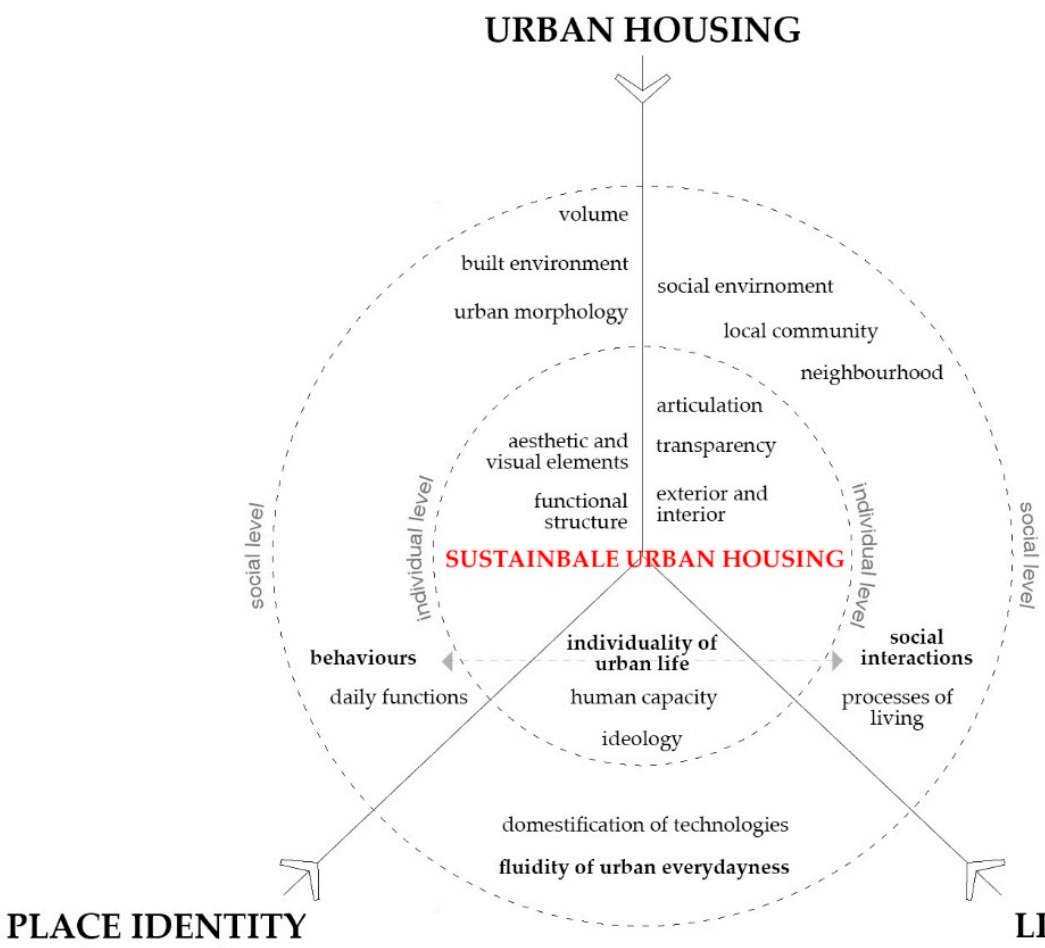

\section{LIFESTYLE}

Figure 1. Conceptual framework diagram of sustainable urban housing: urban housing, place identity and lifestyle perspectives across the social and individual level.

Unstable social conditions, use of modern technologies and changes in the structure of the traditional family have all led to a complex new position of the individual in society. This also brought about the creation of living, working and accommodation spaces in accordance with both self-identity and a common identity. The conceptual framework includes several paradigms for place identity and housing identity: (1) social identity and psychology of place [38-44], (2) phenomenology of the place [20,45,46], (3) self-identity vs. collectivist perspective of identity [47-50], (4) environmental meaning of 
the place and placing home in context [51-53], (5) place change and identity process [11,54], (6) communicating identity and expression of place identity [55-58], and (7) a scale of the place and spatial levels of identity $[59,60]$. These thematic frameworks help to (1) understand the context of development of different approaches in place identity and housing identity research while recognizing the most important authors and publications; (2) identify concepts closely related to the theoretical and methodological framework of place phenomenology, place identity and place change in accordance with housing typology; and (3) define the content and conceptual framework for practical action in the process of designing sustainable housing identities in the contemporary city.

\subsection{Case Study Area}

Belgrade city center is characterized by a heterogeneous urban structure consisting of various typologies of predominantly compact structures within the narrowest city center with a gradual increase in the openness of residential complexes towards the city center boundaries. Multi-family housing architecture within Belgrade city center was mainly built in the first half of the 20th century, but individual buildings were also built during the socialist period, especially in the border areas of the wider city center. In addition, buildings built after the 1990s during a period of transition to the capitalist system. Historically, what was always a specific characteristic of the housing architecture in Belgrade was that housing unit schemes came from European cities and then were adapted to a certain extent to local needs and lifestyles. This fact was characteristic of the architects of both modernist and eclectic orientation [61]. From the aspect of contemporary development (after 1990), housing is determined by the restrictive conditions of the open market economy. Made for a society of consumers, a potential variety of organization schemes is standardized according to the best-selling options, producing an unrecognizable mass of commercial housing without the humane element. Architectural production has had to adapt to rapid and unexpected social and political changes. This period is characterized by a distinct lack of critical thinking, especially in residential construction [61]. This situation further confirms the need for the rethinking and reinterpretation of housing identities.

The case study area is situated in the complex typo-morphological environment of Belgrade city, characterized by valuable historical, cultural and social features and a specific urban framework. The position of spatial frameworks for housing design is shown in Figure 2.

The spatial framework assigned to the first group of researchers, "Manjež Park" (Figure 2A), is located in the inner-city center of Belgrade, which has been in the process of transformation and identity-shaping for many years. The focus of this location is the "Slavija Square," which is a gravitational zone for various city activities and the cross-flows of everyday life. The other spatial framework, "Čubura Park" (Figure 2B), is situated in the immediate vicinity and represents one of the old, historic cores positioned on the border of the inner-city center of Belgrade that has transformed from a village to an urban neighborhood. In recent years, this territory has undergone an intensive process of densification and transformation. Both spatial frameworks are characterized by a specific morphology, ambience and identity, seeking to transform in accord with contemporary trends. Positions of the locations for housing design in a gravity framework are shown in Figure 3. 


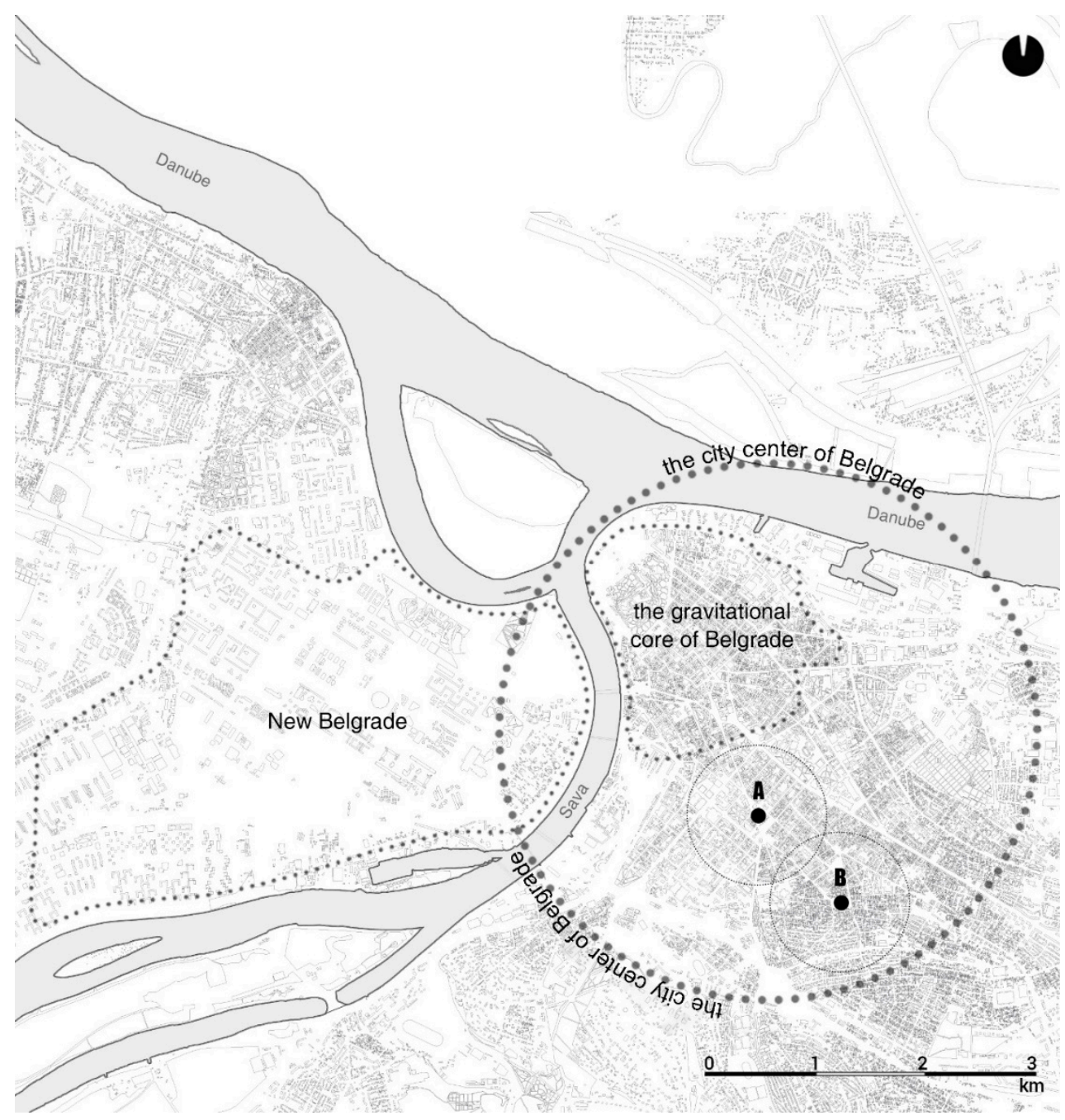

Figure 2. Spatial frameworks for housing design: (A) “Manjež Park" and (B) “Čubura Park."

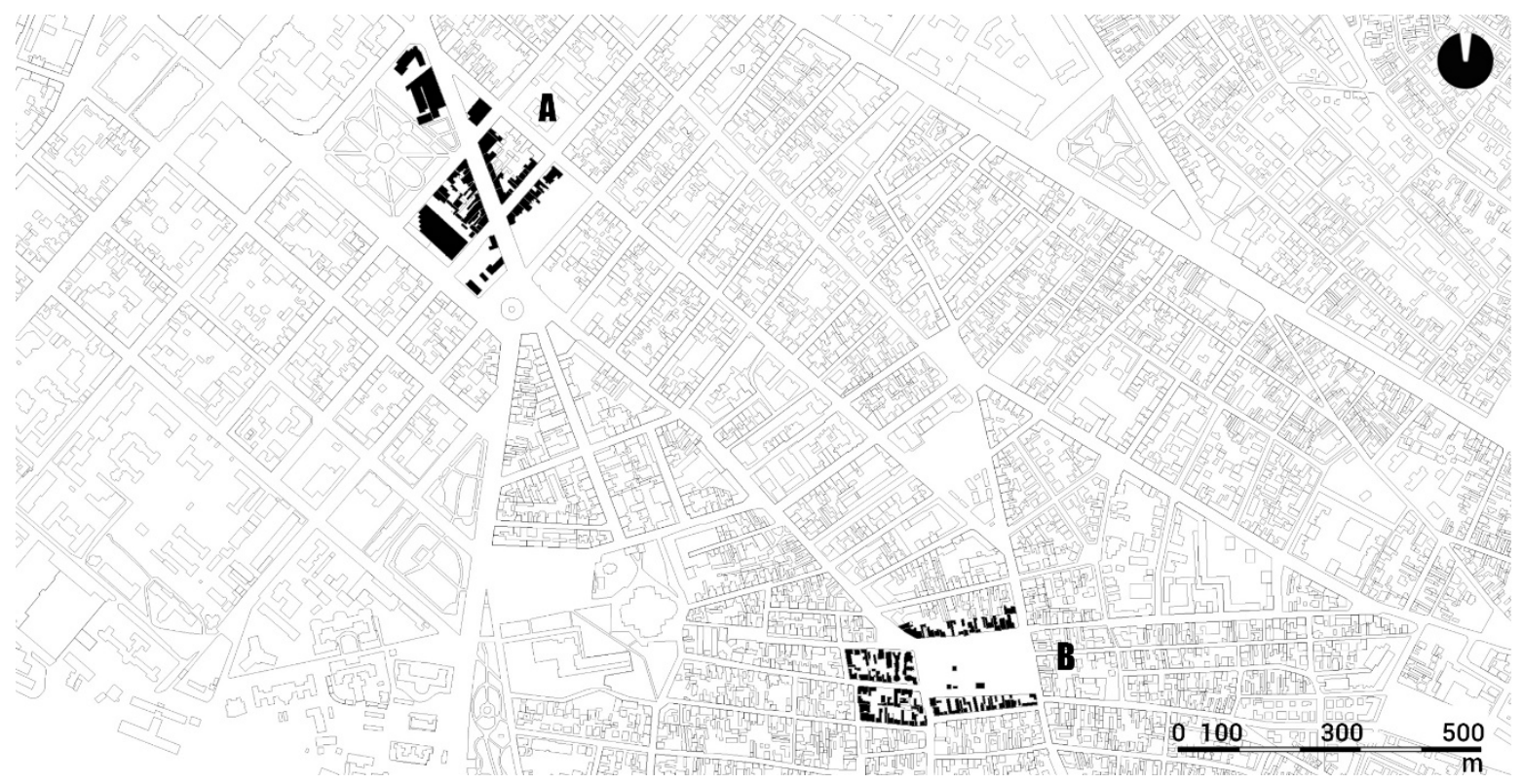

Figure 3. Locations for housing design in a gravity framework: (A) Slavija Square, (B) Čubura Park. 


\section{Findings and Discussion}

The research findings are presented through a critical discussion of the conducted research based on both research perspectives presented in the methodology-scientific research and research by design - as well as on exploration and explanation outputs in accordance with the research phases. First, the Role Models (three for each location) of future housing identities are presented through an explanation of the basic conceptual determinants and housing scenarios in line with contemporary sustainable lifestyles. In addition, for each of the Role Models, graphic illustrations of design proposals will be presented through three spatial levels - urban morphology, architectural and functional articulation, and ambient sequences. The presentation of the Role Models is followed by their comparative analysis in accordance with defined criteria that include (1) a platform for the creation of a specific place character able to engage a diverse community (global village), (2) an overlap between the urban and individual dimensions of life, and (3) transgression into a new life-form. The final part of the findings is built on a discussion of general scenarios for future housing identities through a reference to Role Models and an explanation of the foundation and character of the architectural program, and nexus between place and identity.

\subsection{Identification of the Role Models of Future Housing Identities}

The scope of the design within our Housing Design Studio is concerned with the elaboration of conceptual housing projects which incorporate program and spatial complexity with an integral application of knowledge from both a technical, engineering and technological perspective and a social, humanistic and artistic perspective. This study focuses on the design and regeneration of the urban city block mainly intended for housing typologies with predominantly multifunctional, educational, cultural, business, sports or trading purposes. Regarding the structure of spatial frameworks, the position of the site imposes a diverse range of design research questions. In this sense, the research level of the project has required designers to study not only design and program features but also all the other (sociological, historic, technological, technical, behavioral, economic, etc.) determinants that define the identity of the urban block. More specifically, this was an attempt to analyze and highlight the future characteristics of the architectural, urban and socio-cultural physiognomy of the urban block through its specific relationship with the environment and users.

\subsubsection{Role Model 1: Living in a Bubble}

This concept aims to facilitate a group of active urban inhabitants whose lifestyle is defined through personal identity and mobility. The main residency feature is imagined as a sort of "boutique hotel" with the additional range of urban amenities and facilities (program+) scattered randomly or incidentally throughout the structure. Space is created as a kind of infrastructure filled with mobile units where the choice of position and content, as well as capacity of the insula, is menu-based. This means that each inhabitant chooses the micro-location and particular program + that he/she wants to be close to (a la carte system). The permeable cluster in which communications are exposed to the public view, and the private space is reduced and cocooned, points to the paradigm of the contemporary everyday life in which accidental encounters play an important part in the inhabitant's daily routine (Figure 4 ). 

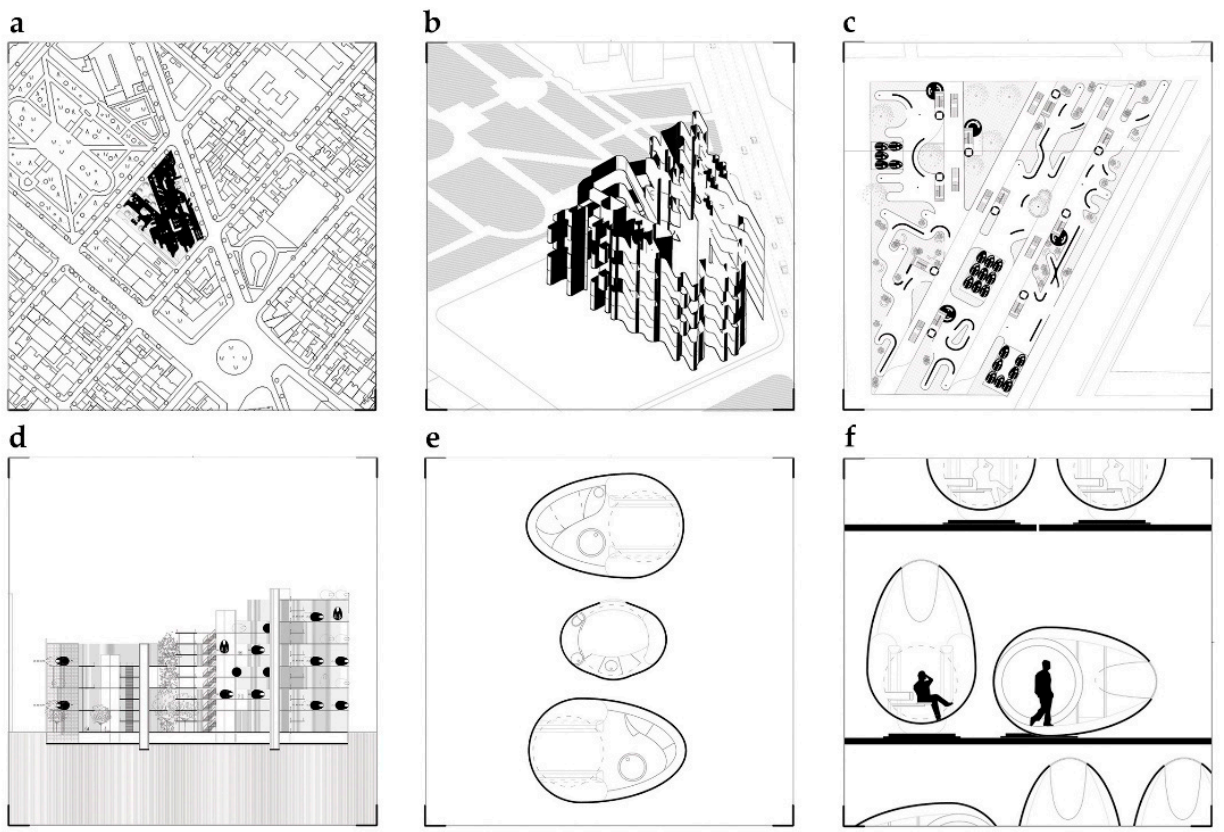

Figure 4. Role Model 1: Living in a bubble (Location A). (a) site plan, (b) volumetry, (c) building plan, (d) building section, (e) housing unit plan, (f) ambience sequence. Student: Tijana Radovanović.

\subsubsection{Role Model 2: Custom-Made Housing Landscape}

This concept is based on the reinterpretation and re-examination of the relationship between public spaces and housing units, as well as the desire to design flexible and unique housing units for different user groups. The focus is on the design of a custom-made housing landscape to enable horizontal and vertical stratification of public spaces and their direct connection with all housing units through the simultaneous gradation of privacy. In this way, the aim is to increase the compactness and density of housing, but this housing complex also becomes a platform for the creation of a specific place character able to engage diverse communities. The result of this approach is a space of different gradients of the sociability of space-from individuality to an interactive community. This particular concept feature is based on attraction, accessibility and openness (Figure 5).
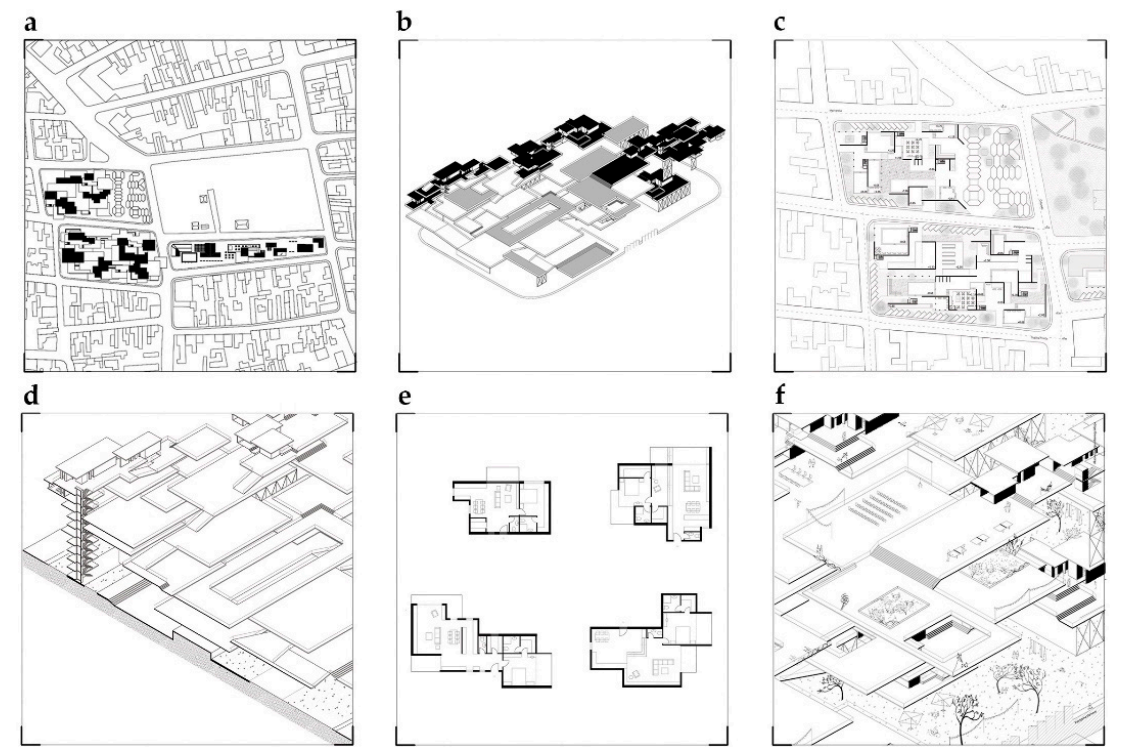

Figure 5. Role Model 2: Custom-made housing landscape (Location B). (a) site plan, (b) volumetry, (c) building plan, (d) building section, (e) housing unit plan, (f) ambience sequence. Student: Aleksandra Stijović. 


\subsubsection{Role Model 3: Living Station}

The concept emphasizes the networking of all levels of mobility; from local, where hallways represent the show-windows of life, to urban and regional where housing is mixed and integrates shops, leisure facilities, recreational facilities, different services, business and metro, bus, and train stations. No one can recognize and distinguish between inhabitants, commuters and facilitators. It is a kind of man-hive where the movement takes on the role of the basic principle, and the structure of the units is determined by the partitions and ducts. The simple structure, whose flat façade canvases represent endless digital screens, leads to the question that life is only the background of the urban representation of 21st century man (Figure 6).
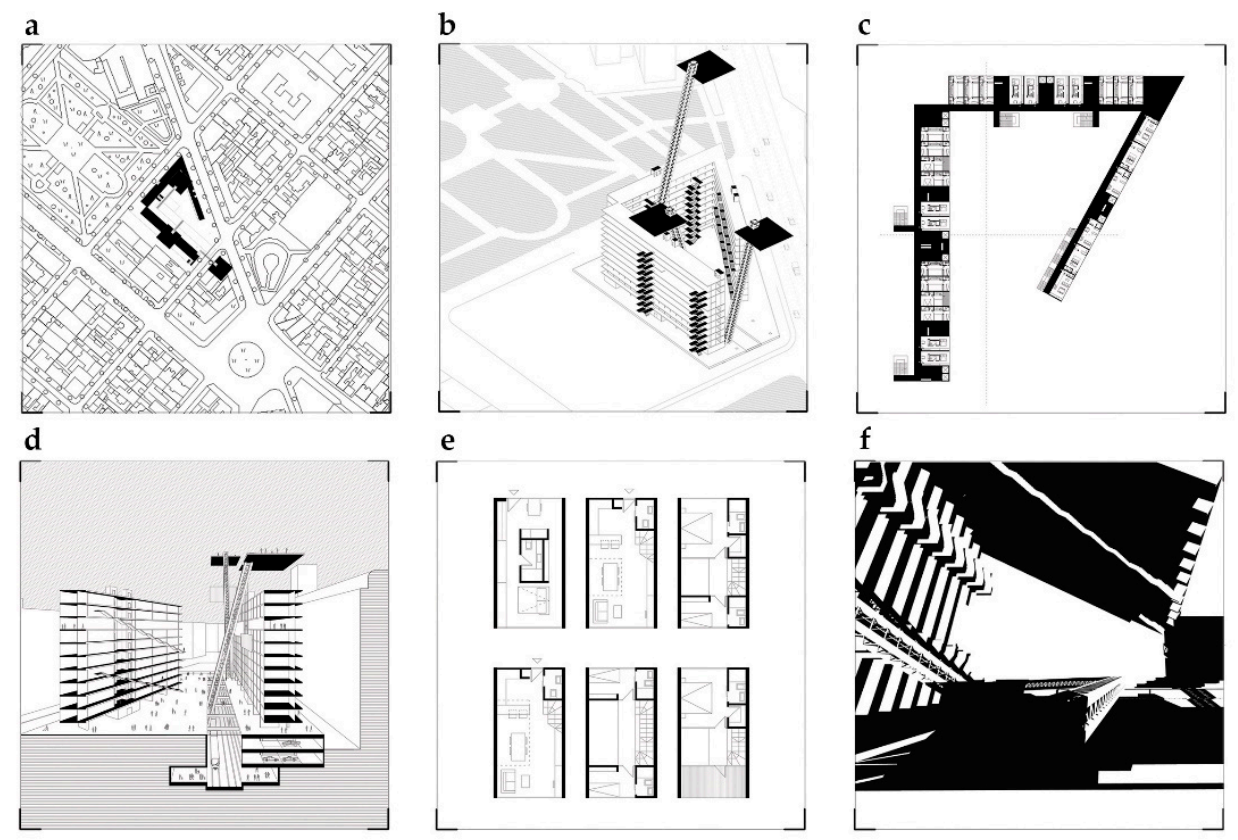

Figure 6. Role Model 3: Living station (Location A). (a) site plan, (b) volumetry, (c) building plan, (d) building section, (e) housing unit plan, (f) ambience sequence. Student: Aleksa Bekić.

\subsubsection{Role Model 4: Housing as an Infrastructure for Generation of New Urban Identity}

The concept starts from the assumption that the structure of the housing is a very important element in generating future urban identities in accordance with the changed requirements, behaviors and everyday life of the inhabitants of the city center. The project is focused on re-examining the principles of designing traditional ambiances and densities of residential structures in the traditional city center, but also their relationship with the specific and very individualized needs of new urban life patterns. The design approach in this sense is based on a reinterpretation of the theme of traditional urban patterns of housing structures in the city center. Patterns are interpreted as equally spatial, social and cultural constructs. The spatial concept is characterized by a very specific approach to the flexibility and adaptability of the interior space of residential units, as well as the flexibility, diversity and attractiveness of the ambiance of open public spaces (Figure 7). 


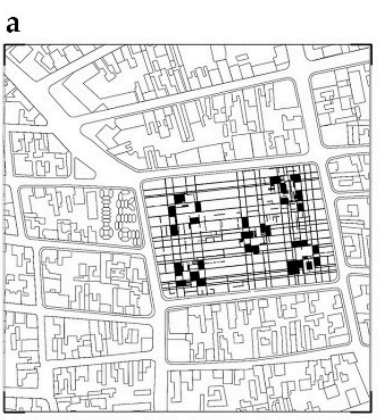

d

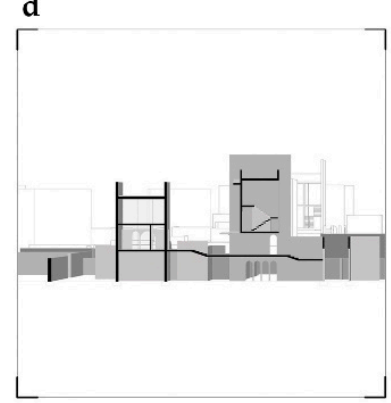

b

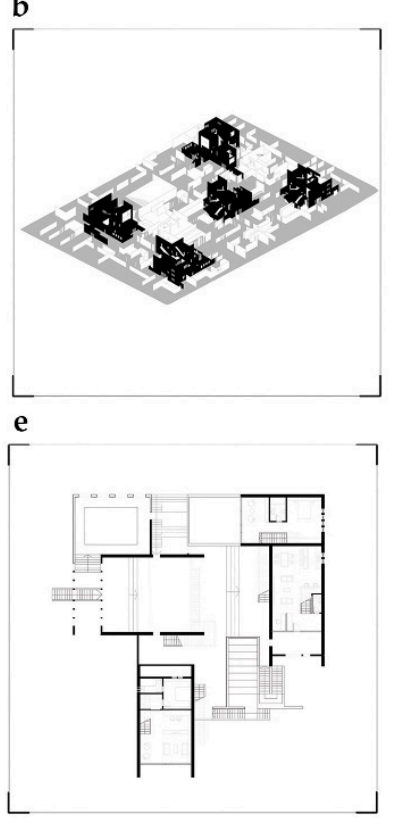

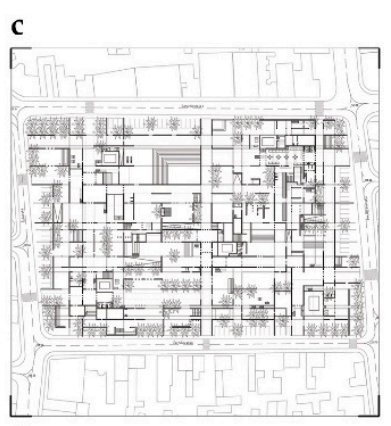

f

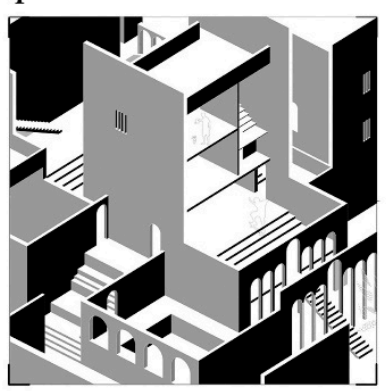

Figure 7. Role Model 4: Housing as an infrastructure for generation of new urban identity (Location B). (a) site plan, (b) volumetry, (c) building plan, (d) building section, (e) housing unit plan, (f) ambience sequence. Student: Mladen Ostojić.

\subsubsection{Role Model 5: Dream-Family Factory}

The concept intends to meet the needs of the newly created 21st century family. The main housing feature leans on the good modernism tradition interpreted in a fresh and contemporary way as a juxtaposition between residency, education, recreation and relaxation with the addition of work united at the block level. The revision of the 20th century socialism lifestyle transforms into the new model of co-housing, where neighbors help and encourage each other and jointly support one another in building a small, sustainable and responsible ecosystem. The concept satisfies all the needs of young families of diverse structures while opening new possibilities for the integration of family life and city life through flexible common spaces. Accordingly, the maximally used spatial capacity of the residence "lamella" ensures the minimum occupancy of the plot. Although partially closed, the central space intended for games and entertainment is a place that the city can enter only if it knows the right door (Figure 8).
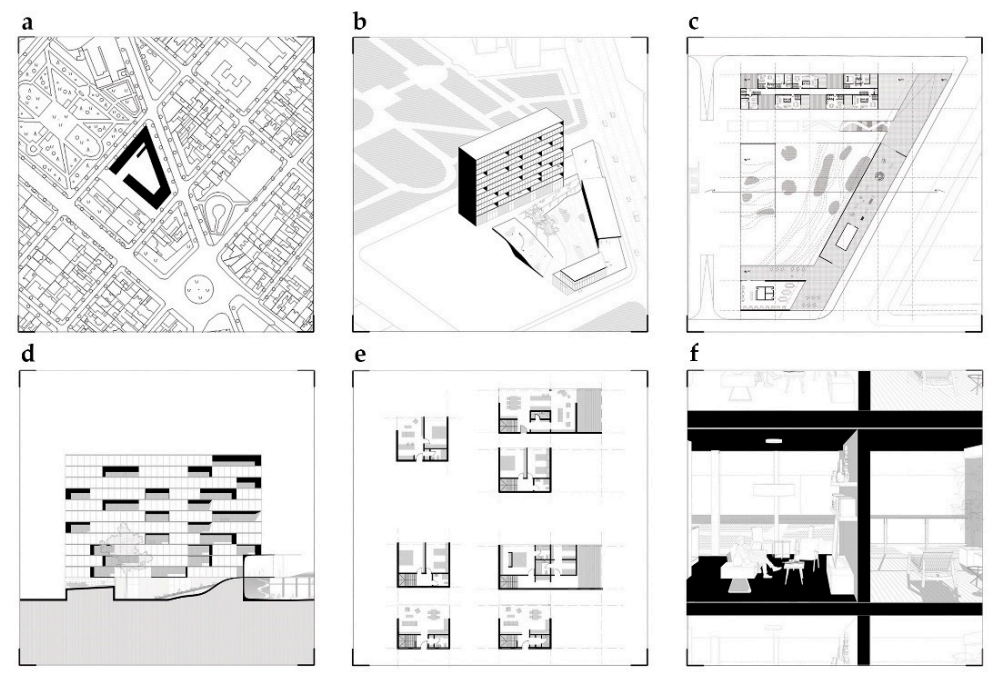

Figure 8. Role Model 5: Dream-family factory (Location A). (a) site plan, (b) volumetry, (c) building plan, (d) building section, (e) housing unit plan, (f) ambience sequence. Student: Pavle Nikolić. 


\subsubsection{Role Model 6: Reinventing Minimum Dwelling}

This work challenges the issue of the architectural minimum within the housing typology. In this sense, the focus is on the new standards for the design of housing units and the structure of the housing complex itself through the re-examination of conventional anthropometric measures. In terms of programming, the concept is based on the duality of housing and work, as well as their articulation through a specific communication system and increased transformed mobility. The design of the building in accordance with the theme of the architectural minimum is not expressive and strives for neutrality (Figure 9).

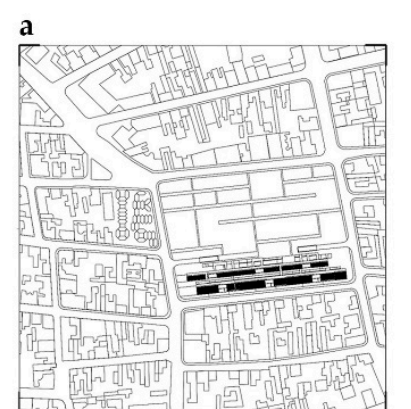

d

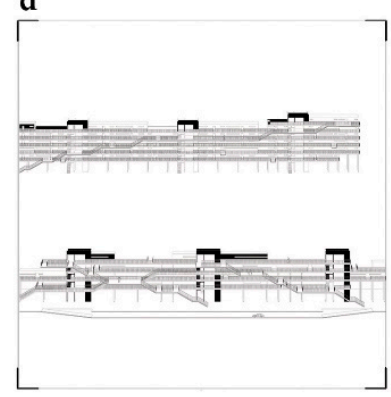

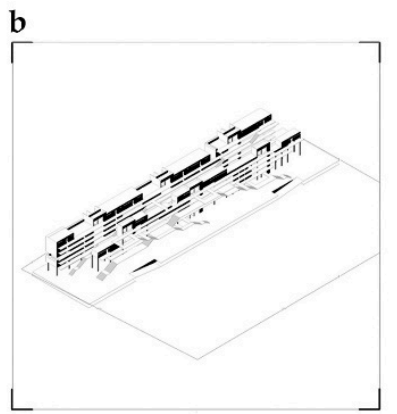

e

$$
\text { e }
$$

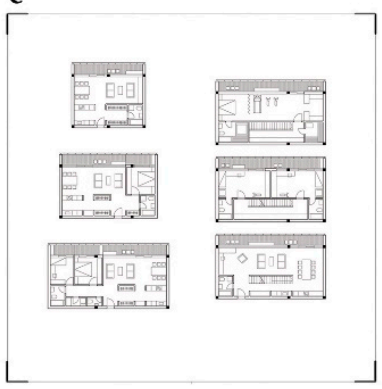

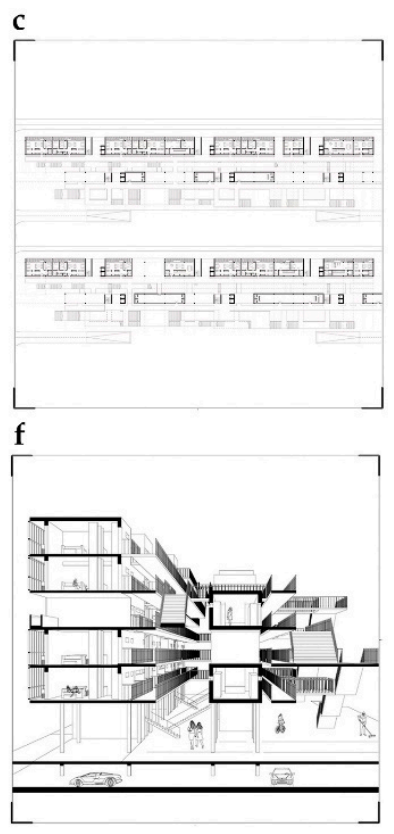

Figure 9. Role Model 6: Reinventing dwelling minimum (Location B). (a) site plan, (b) volumetry, (c) building plan, (d) building section, (e) housing unit plan, (f) ambience sequence. Student: Nikola Mitrović.

\subsection{Qualitative Data Analysis of Role Models}

On account of the criteria that originated from theoretical discussions and students' experience of the urban way of living and differences that emerged during the 21st century, a multiple comparative analysis was formed. Based on the multiple comparative analysis of students' research designs (Table 1), it can be noted that flexibility and integration of various contents in the organizational and spatial structure is always present but not decisive. On the other hand, accessibility of residency is much more open, multi-leveled and fragmented, as well as plural in a spatial and semantic sense, enabling various readings of the space and fulfilling diverse residents' lifestyles. Thus, a clear attitude towards an overlap between urban and personal dimension of life is always emphasized. It is present in the vast majority of concepts, although a new life-form considering domestication of media technology and digital change in everyday patterns is either too emphasized or not relevant. Increased and transformed mobility is present at a very high level, but it is not a defining element of the concept. It is implied as a necessity but not developed in a conceptual way. All research designs explore borders of permeability and adaptability as basic determinants of the modern way of urban life, where only a permanent change in the good tradition of Bauman fluidity [12] is guaranteed. Permeability of different aspects of life has become commonplace and somehow always present, but the interest in seeking new forms of integration has not changed. The image of traditional family has vanished, albeit some sort of structured community is still the backbone for the majority of concepts. Emphasizing identity through housing is evident in a small number of designs. There are a 
number of designs that change the scope of housing programs but stay fairly traditional when it comes to spatial features of the place.

Table 1. Qualitative data analysis of Role Models.

\begin{tabular}{|c|c|c|c|c|c|c|c|c|c|c|}
\hline \multirow[b]{2}{*}{$\begin{array}{l}\text { Role } \\
\text { Model }\end{array}$} & & \multicolumn{3}{|c|}{$\begin{array}{l}\text { Criteria } 1 \\
\text { Platform for the Creation of } \\
\text { Specific Place Character Able to } \\
\text { Engage Diverse Community } \\
\text { (Global Village) }\end{array}$} & \multicolumn{3}{|c|}{$\begin{array}{l}\text { Criteria } 2 \\
\text { Overlapping of the Urban and } \\
\text { Individual Dimensions of Life }\end{array}$} & \multicolumn{3}{|c|}{$\begin{array}{l}\text { Criteria } 3 \\
\text { Transgression into a New } \\
\text { Life-Form }\end{array}$} \\
\hline & Location & $\begin{array}{l}\text { 1.1. Flex- } \\
\text { ibility, } \\
\text { Adapt- } \\
\text { ability }\end{array}$ & $\begin{array}{l}1.2 . \\
\text { Accessi- } \\
\text { bility, } \\
\text { Open- } \\
\text { ness }\end{array}$ & $\begin{array}{l}\text { 1.3. Inte- } \\
\text { gration: } \\
\text { Work- } \\
\text { Leisure, } \\
\text { Work- } \\
\text { Family }\end{array}$ & $\begin{array}{l}2.1 . \\
\text { Demo- } \\
\text { graphic } \\
\text { Change, } \\
\text { Family } \\
\text { Struc- } \\
\text { ture }\end{array}$ & $\begin{array}{l}2.2 . \\
\text { Densifi- } \\
\text { cation, } \\
\text { Com- } \\
\text { pactiza- } \\
\text { tion }\end{array}$ & $\begin{array}{l}2.3 . \\
\text { Alterna- } \\
\text { tive } \\
\text { Lifestyle }\end{array}$ & $\begin{array}{l}3.1 . \\
\text { Domes- } \\
\text { tication } \\
\text { of } \\
\text { Media } \\
\text { technol- } \\
\text { ogy }\end{array}$ & $\begin{array}{l}\text { 3.2. In- } \\
\text { creased } \\
\text { and } \\
\text { Trans- } \\
\text { formed } \\
\text { Mobil- } \\
\text { ity }\end{array}$ & $\begin{array}{l}3.3 . \\
\text { Chang- } \\
\text { ing } \\
\text { Patterns } \\
\text { of Every- } \\
\text { day } \\
\text { Life }\end{array}$ \\
\hline 1 & A & $\bullet$ & + & + & • & - & • & + & + & + \\
\hline 2 & B & + & • & $x$ & + & - & + & $x$ & $x$ & - \\
\hline 3 & A & + & + & $x$ & + & - & $x$ & $\bullet$ & - & + \\
\hline 4 & B & $\bullet$ & $\bullet$ & + & $x$ & $\bullet$ & $x$ & $x$ & + & + \\
\hline 5 & A & + & + & $\bullet$ & - & + & - & $x$ & $x$ & + \\
\hline 6 & B & + & + & $\bullet$ & + & + & - & $x$ & + & - \\
\hline
\end{tabular}

Index: - -negative attitude; +-positive attitude; $x$-irrelevant; $\bullet-$ particular concept feature.

Comparing designs in relation to location, it is evident that housing in the city epicenter (Location A) is more oriented towards permeation of dwelling and public facilities and refers to temporary residences and housing based on urban facilities. In addition, housing within the inner-city center is hidden behind layers of communication, informational and other activities characteristic of high-urbanized areas and concisely in the organizational structure; it looks more like a dormitory. On the other hand, the housing structures of location $\mathrm{B}$, which is located on the borderline of the city center, are characterized by the desire to engage diverse communities and insist on densification through a re-examination of traditional urban patterns of housing structures. Among these concepts, there is a tendency to achieve some of the qualities of single-family housing in terms of the relationship between private and public space. In the treatment of the physical structure, there is also a tendency towards fragmentation of wholes, towards much more open and fluid spaces, as well as a tendency towards achieving dynamism and individualization of individual spaces through a continuous change of different ambiances. This is especially characteristic for Role Models 2 and 4 . It may be said that the presence of media technologies is then closer to the Slavija Square location, as well as mobility, which is understood as flexibility in relation to rapid changes in the places of residence.

To summarize, students' research designs differ in terms of program, form and space. Negotiating with the urban pattern, whether by leaning on or against it, has proposed architectural solutions that structure the space with more flexibility towards unpredictable future uses. It is evident that the integration and interlocking of various urban-public and personal-private contents offer a unique architectural expression that creates identities for a sustainable lifestyle, and provides a unique flexible, attractive and accessible cosmopolitan urban landscape. None of the students' achievements should be considered for the image they represent, but for the spectrum of various performances they offer, with a relationship to the inherited structure, degree of animating the urban scenery, and importance of establishing a dialogue between the private and public domain of urban life. By exploring the relationship between housing and place identities through architecture, 
and by emphasizing their harmonization, we concluded that the meaning of any building goes beyond a mere object, becoming a part of finely structured urban housing system.

\subsection{Scenarios for Future Housing Identities through Comparative Analysis of Role Models}

Results of the housing design projects distinguish three thematic frameworks that differ with respect to the approach in which the concept was founded and the design principles for future housing identities:

- meta-housing,

- custom-made habitation,

- maximal minimum.

In creating adaptive open-ended contents and building flexible individual units ready to be interlocked or separated when needed, all these concepts seem to operate under the assumption of a strong demographic change in the urban family. A great majority of designs domesticate technology in all aspects of everyday life, from facilitating home contents to controlling the level of fusion between the urban and private life. Mobility, whether seen as a personal choice of the user or as part of the overall structure, is evident and visually present. Some of the concepts insist on the integration of work and leisure facilities, while others hint at something we could call "program+" [62]. It is a kind of added value to the housing model proposed by the design. The idea of the program is manifested as a series of research questions based on the migration of social, cultural and environmental forms of research and increasing interest in the spatial potential of new typologies or the evolution of existing typologies of housing [63]. It can be said that all five points of departure are coherently joined and included in the concept.

\subsubsection{Meta-Housing}

Founded on postmodern thinking and focused on building a specific, creative neighborhood, the concept provides socially unique, attractive, semi-accessible (and sometimes even gated) communities, in which dwelling, apart from housing, implies a variety of urban amenities and utilities, usually in the good tradition of urban regeneration policies [11] (Figure 10).

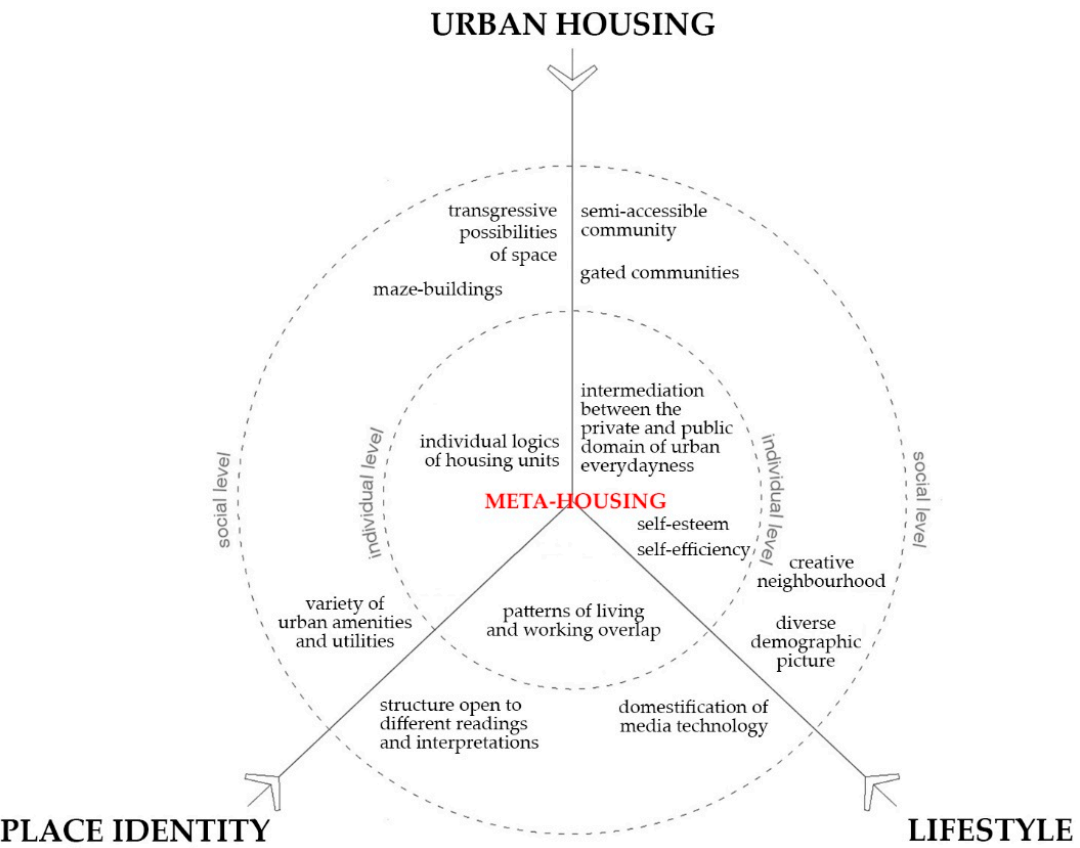

Figure 10. Conceptual framework diagram of meta-housing scenario: urban housing, place identity and lifestyle perspectives across social and individual levels. Source: Authors. 
Programming focuses on a diverse demographic picture and domestication of media technology [14]. Mobility is both literal and phenomenal; a matrix or a maze-building has its own individual logics. Patterns of living and working overlap. Housing identity is modeled through individual lifestyle, thus creating a structure open to different readings and interpretations [17].

The place is an intermediator between the private and public domain of urban everydayness, focusing on all those transgressive possibilities that space can offer. Architecture is a link and a communicator between the city and the people. It is a vast and dense territory where limits and scales overlap. The life around the dwelling is the major focus of design, promoting the concepts of intertwining and interlocking.

Place identity is marked by self-esteem, self-efficiency and distinctiveness. The students' design for the meta-housing balances the concept between being oriented toward the local community and being urban (i.e., being open for visitors). Role Model 5 shows this binary positioning where housing is directed towards urban contents through the integration of housing and work, opening housing to public activities and facilities; and on the other hand by designing a large number of accompanying social standard facilities that meet the needs of local residents by providing a homely ambience that is a twisted ambience of a hidden interior and a safe pastime. Role Model 1 shows the same binary positioning residency against urban amenities. These design principles are also relevant for Čubura Park location. We can see that the dwellings in Role Models 2 and 4 are also intertwined with other functions, amenities and activities both horizontally and vertically. Individual housing units differ from each other both in form and in function, thus creating a home for different demographic structures of users and enabling a specific identity of every housing unit and settlement at the same time. This is very important from the aspect of identification of users both with the settlement and with their apartments.

Meta-housing easily adapts to different conditions of place identity. Through principles of flexibility, integration and densification, a specific lifestyle is formed with respect to the conditions of micro-location, and is adequate for the conditions of Belgrade in which the heterogeneity of the city structure is one of its basic features.

This type of scenario in its social framework engages a user profile that seeks identity and relation between the private and public spheres of urban everyday life through the cultural-historical core and specific wholes of pronounced morphological characteristics. Accordingly, the structure of the housing includes the gradation of public and private spaces to provide a spatial interface for the integration of different users regardless of their background in accordance with age, family structure, interests, profession, patterns of habits, etc. In that sense, the role of public space as a polygon for creating a housing community in which users exchange values and build a specific lifestyle in the city center is especially affirmed.

\subsubsection{Custom-Made Habitation}

Founded on post-structuralist Rhizomatic schemata and baring its concepts from repetition and difference [64], it is above all an infrastructural concept based on a futuristic film aesthetic, with mobility and domestication of media and Internet technologies as its prime forces (values) (Figure 11). Customization of the housing cell is its main component, and the architectural logic highlights the process of living in it, rather than the product of architecture. This model is in line with contemporary tendencies of sustainable development in terms of responding to the personalized needs of individual users [8]. 


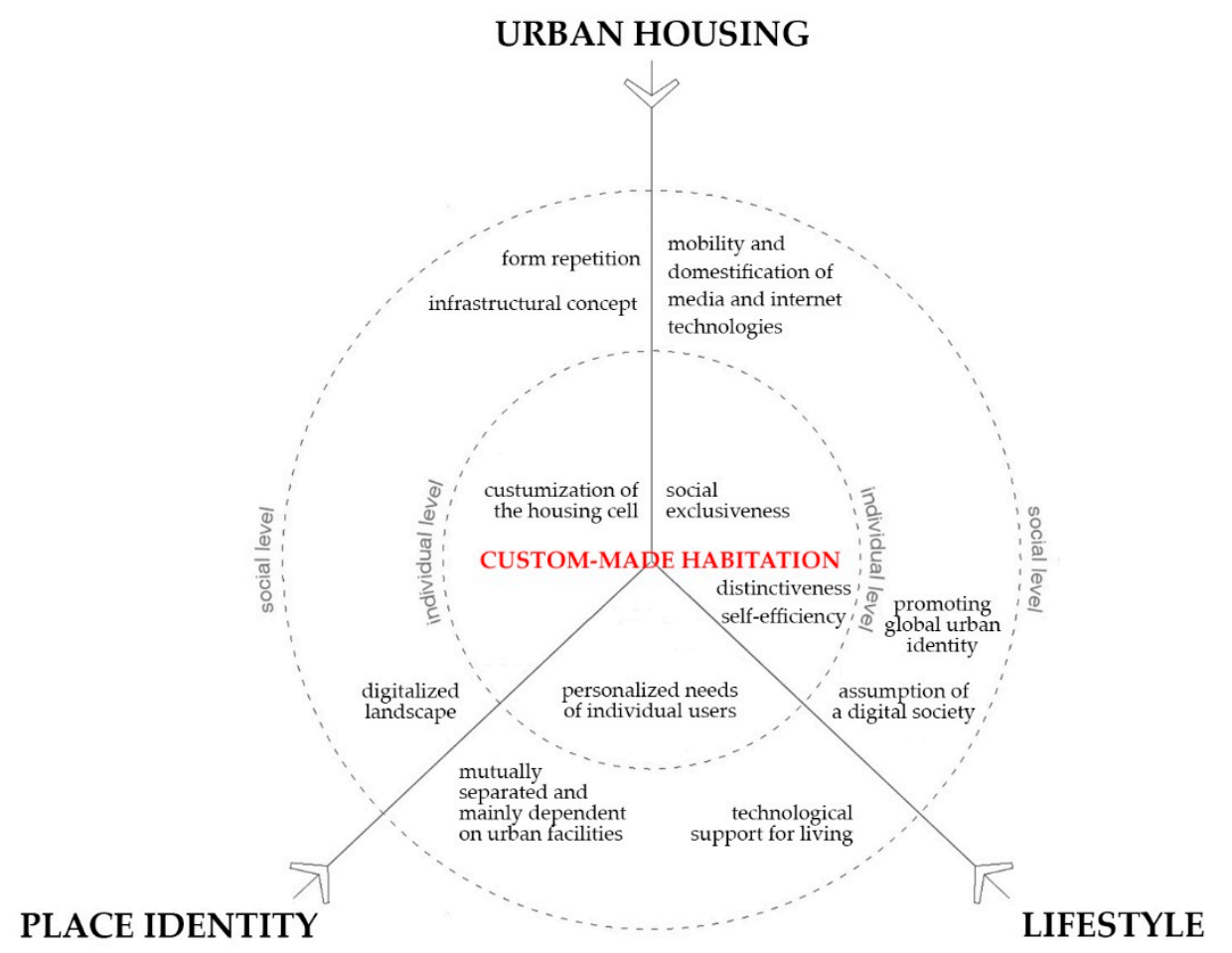

Figure 11. Conceptual framework diagram of custom-made habitation scenario: urban housing, place identity and lifestyle perspectives across social and individual levels. Source: Authors.

Programming focuses on individual custom-made units ready to be shared, interlocked and ungraded. Technology and mobility are literally an integral part of the housing strategy. Patterns of living, working and leisure are mutually separated and mainly dependent on urban facilities. Housing identity has a unique symbolic character creating a kind of heterotopia open to those who know how to enter and use the place properly.

The place itself is a digitalized landscape. It is precise and clear in its appearance and somehow deterministic in its social exclusiveness. The life is based on the assumption of a digital society, upon which the whole concept is built. On the other hand, there is no prescribed hierarchy, instead of which alteration is present.

Place identity is marked by self-efficiency and distinctiveness. The students' design results for the custom-made concept show a high level of independence from the immediate surroundings, mobility in terms of provisional residency and a high level of media domestication where the house is a technological support for living. Role Model 1 shows how much customization, mobility, temporality and ephemerality can become part of the concept. A la carte residency becomes an active participant in urban life promoting a cosmopolitan resident. On the other side, the result of Role Model 2 is a custom-made housing landscape that is very open and flexible, both at the scale of the settlement and on the scale of individual housing units. The housing structure is layered, and at the same time the housing units are of different sizes and structures, thus enabling a specific effect of spontaneity in development, diversity of ambiance and heterogeneity of users.

Custom-made housing is prone to being transformative in its concept, so it can easily adapt to diverse contexts and place conditions. Therefore, it is highly suitable and best in promoting global urban identity with a touch of locally appreciated flavor.

This scenario in its social framework engages a user profile that is facing dynamic structures, with changeable and adaptable character according to the model of a postindustrial and compact city with high frequency and intensity of activities. This profile insists on the space of fast communication and flow of information through the urban structure of a multifunctional city. The heterogeneity of the functional structure, new contents and typologies thus represents one of the basic characteristics of this type. 


\subsubsection{Maximal Minimum}

Founded on modernist legacy and aiming at adaptability and variability through the concepts of reduction and flexibility, it provides a place for various life scenarios, as well as changes during their existence (Figure 12). It is above all a system, or a pattern that can easily adapt to the present and future needs of inhabitants without changing its basic identity [15]. Thus, it is in line with the contemporary urban sustainability request to be flexible enough to respond to short-term needs while considering a long-term view of development.

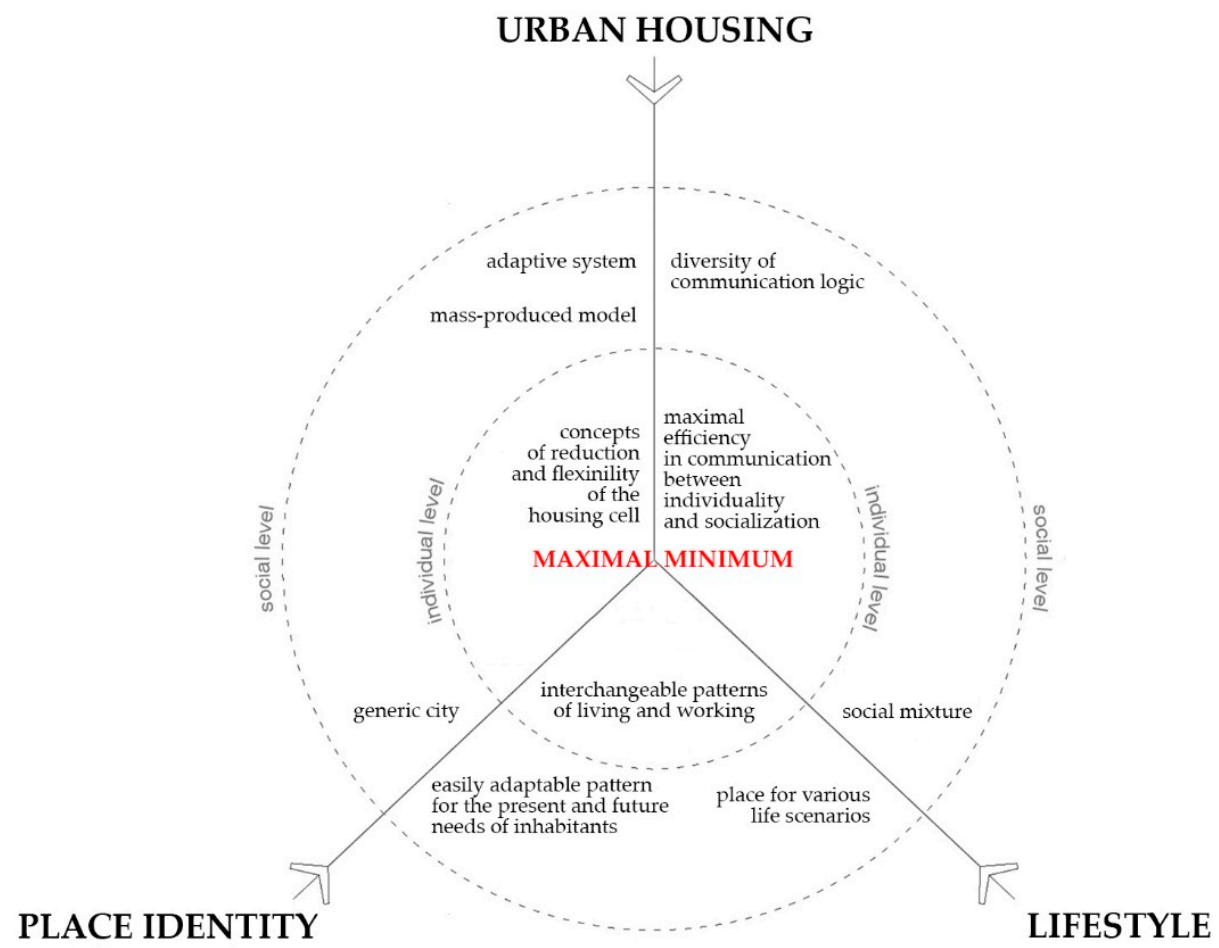

Figure 12. Conceptual framework diagram of maximal minimum scenario: urban housing, place identity and lifestyle perspectives across the social and individual level. Source: Authors.

Programming is a model defined. Mobility is phenomenal, meaning that a limited number of transformations create the structure. Patterns of living and working are interchangeable; therefore, it is not possible to distinguish whether the structure comprises housing, working, leisure, or any cultural or other urban programs. Housing identity is merely urban identity, fluid and adaptive.

The place is a pure generic city, without a historical reference or a sole typology. In contrast to custom-made habitation, a housing cell is a mass-produced model, universal and global. Its main architectural element is a sort of "Container BOX," focusing on diversity of communication logic between the individual and public dimension of the place [13]. It is undetermined and symbolizes the dwelling as an unfinished process. The life is based on the concept of a social mixture, and possible physical alternation of the place cannot give a specific place identity, releasing and freeing architecture from its deterministic dimension.

Place identity is marked by continuity. The students' design results for the maximal minimum concept are highly rational on one side, but also extremely flexible on the other While Role Model 3 looks for the adequate spatial boundaries that can match different content from residency and working, to public facilities and businesses, Role Model 1 finds its maximal minimum in program+ arrangement where one can choose needed facilities that can complement basic private residency. Role Model 4 finds its maximal minimum in compact minimal housing units, but maximal efficiency in communication between individuality and socialization, between private dwelling spaces on one side and complementary facilities with public spaces on the other side. 
Maximal minimum, above all, follows the traditional modernist tradition exploring its interpretations. It is traditional in organizational and spatial articulation, but contemporary in its content arrangement and context utilization.

This type of scenario in its social framework engages a user profile that links life in the city center to an intense relation of life and work. A significant role in this sense is played by new professional profiles that engage work from home or temporary residence for work, which is why housing is based on the concept of maximal minimum. In that order, housing has a private-family and public-social sphere and implies the satisfaction of family and social (vital and cultural) needs, and the individual is involved in the housing process through the individual sphere of the house and the collective sphere of work.

\section{Conclusions}

The concept of housing identities as a dynamic socio-technical network provides an analytical framework that enables us to deal with future design challenges. It is essential to understand how housing identities change and develop design strategies. The concepts of meta-housing, custom-made habitation and maximal minimum can be used to improve the social aesthetic of future cities, tracing a way towards sustainable housing patterns in line with mobility, adaptability, domestication and participation.

After discussing all three approaches, we can conclude that although the design varies in scope and size, they all have two principles in common. The first one is increasing mobility across all possible levels of the concept. The second one is adaptability to unpredictable changes caused by urban development, evolving through formal customization, program reduction, and flexibility or content fluidity. In addition, a fact that is mutual to all these designs is that architecture stands as a communicator between the individual, semi-public and public everyday life, exposing personal lifestyles in different frameworks with a focus on designing relations, communication and ambience rather than exact contents and form.

As this research was conducted using two different locations and contexts, but based on the same approaches, we can conclude that location and context change the way in which each design is conducted. Therefore, future housing identities are grounded in the notions of meta-housing, custom-made habitation and maximal minimal, but they still are considered together with the relevant location and context.

Housing identities are defined by both material and non-material features. In this sense, the contemporary understanding of sustainable housing and its basic values, particuarly those connected to the meaning of home and dwelling, seems to be deeply rooted in society and thus cannot be easily modified. There exists a certain common understanding of how the unit is conceptualized through security, continuity, control and a reflection of self. In contrast, the articulation of content and context is prone to transformation and is more easily dealt with in respect to mobility, changing patterns of everyday life and distinguishing a lifestyle. In this way, a new future housing culture is created, both as a material structure and a socio-economic condition carrying ideas, meanings and values for future urban cultures. The research gives answers to how the built environment influences living practices and conceptualizes the role of architecture, not only as a cultural expression but as a factor in the process of continuous cultural modification. The paper concludes that future housing identities imply active involvement of people and their environment through architecture, which is adaptive, mobile and transparent in its program and ephemeral and illusive in its form.

Hence, housing can be used as a strategy and a tool that positively affects identity and at the same time generates future identities. Architecture could accelerate motivation and hope among inhabitants that live according to personal prospects and lifestyle; thus, it can be implemented in urban housing agendas. There is a need to provide a sustainable housing culture which can fulfil the needs of the present without compromising the ability of future generations to meet their own needs [65]. 
Typo-morphological, spatial and functional organization of housing is burdened by numerous problems that appear as a result of overcrowding in urban areas, continuous diversification of lifestyles, polarization of society with the danger of increasing social segregation, overlapping places of residence and work, population mobility, aging, migration, conflicts in housing, as well as environment, climate protection and other environmental requirements. Changed social conditions, the influence of contemporary technologies and changes in the structure of the traditional family result in fewer apartments representing the "home" of the classical nuclear family. In addition, variations in lifestyles are reflected in increasing demands for apartments for different households/families and social groups, adaptable housing structures to different demographic characteristics, innovative concepts and integrative housing design strategies. The analysis of characteristic housing units shows a tendency of greater complexity in everyday activities with a simultaneous decrease in the number of spatial determinants that define them. Reduced content differentiation increases the possibility of their overlapping and permeation, i.e., the possibility of flexibility and adaptability of the functional organization. Unlike the precise specialization of space according to activities typical for apartments built in the early 20th century, the functional organization of a contemporary apartment is characterized by a multifunctional and neutral living space that allows flexibility and variability in relation to the different lifestyles of users [66].

This research contributes to the establishment of initial scientific knowledge about the potentials of contemporary urban lifestyles as a problematic and critical field of analysis in the process of housing design, but certain limitations of research can be singled out which also generate suggestions and perspectives for further research. Although the study included two locations as case studies, which differ in terms of characteristic morphological and spatial framework, the process of critical context and situation analysis of both locations did not identify specific differences in demographic and social structure, and accordingly in residents' lifestyles. In that order, future research opportunities are reflected in (1) examining the links between sustainable development and contemporary urban lifestyles by challenging it in different contexts, urbanities and situations with heterogenous demographic structure and diversity of social communities, and (2) developing environmentally and culturally sensitive approaches in order to reach a sustainable framework of urban housing typologies. A special research potential is recognized in challenging topics of future housing typologies within the multiscale approach-from the comprehensive territory of the settlements to a single housing unit. The presented findings on six Role Models and three scenarios for future housing identities show that the lifestyle and architecture create a unique and elastic open-ended system with the ability to adapt and change over time and throughout the place. It also shows that the interface between lifestyle and architecture is multidimensional. This multidimensionality opens research perspectives towards decoding and understanding the relations of urban-rural, modern-post-modern, durable-ephemeral, compact-fragmented, public-private and individual-collective, in order to develop design strategies for new housing identities as well as for preserving identities in a process of sustainable urban regeneration. The results of this study encourage practitioners (planners, urban designers and architects) to consider the urban lifestyles within the design process and to find the correlation between (a) changes in the behaviors, daily functions, life cycles and urban everydayness, and (b) built environment, urban morphology and functional structure of space.

Author Contributions: Conceptualization, A.N.; methodology, A.N., J.R.T. and A.M., conducting research as leaders/professors of two student groups within Design Studio-A.N. and J.R.T.; writing — original draft preparation, A.N.; writing—review and editing, J.R.T. and A.M.; visualization, A.M. All authors have read and agreed to the published version of the manuscript.

Funding: This research was funded by Ministry of Education, Science and Technological Development of the Republic of Serbia, grant number 451-03-68/2020-14/200090. 
Data Availability Statement: The authors confirm that the datasets regarding Role Models supporting the findings of this study are available within the article. The datasets regarding 28 initial student designs are available on request from the corresponding author.

Conflicts of Interest: The authors declare no conflict of interest.

\section{References}

1. UN General Assembly. Transforming Our World: The 2030 Agenda for Sustainable Development; United Nations: New York, NY, USA, 2015

2. Ristic Trajkovic, J. The Application of Environment-Behavior Theories in Architectural Design (In Serbian). Ph.D. Thesis, Faculty of Architecture, University of Belgrade, Belgrade, Serbia, 2016.

3. Guy, S.; Farmer, G. Reinterpreting Sustainable Architecture: The Place of Technology. J. Arch. Educ. 2001, 54, 140-148. [CrossRef]

4. Djokić, V. Urban Morphology: City and City Square; Faculty of Architecture, University of Belgrade: Belgrade, Serbia, 2004.

5. Nikezić, A. Transformacija Koncepta Porodične Kuće u Uslovima Regeneracije Gradskog Centra. Ph.D. Thesis, Faculty of Architecture, University of Belgrade, Belgrade, Serbia, 2006.

6. Muxi, Z.; Gutierrez, B.A.; Ciocoletto, A.; Casanovas, R.; Fonseca, M. ¿Qué aporta la perspectiva de género al urbanismo? Fem. Rev. Cent. Estud. Mujer Univ. Alicante 2011, 17, 105-129.

7. Ernawati, J. Dimensions underlying place identity for sustainable urban development. MATTER Int. J. Sci. Technol. 2018, 3. [CrossRef]

8. Sepe, M. Principles for place identity enhancement: A sustainable challenge for changes to the contemporary city. Sustain. City 2012, 2, 993-1004.

9. Manenti, C. Sustainability and place identity. Procedia Eng. 2011, 21, 1104-1109. [CrossRef]

10. Lin, H.-h.; Lee, W. Place Identity for City Sustainability in a Traditional Settlement of Taiwan. Glob. Approaches Divers. 2012. [CrossRef]

11. Cesare, S. Identity, Flexibility and Sustainability for the new Social Housing. TECHNE J. Technol. Archit. Environ. 2012. [CrossRef]

12. Bauman, Z. Liquid Life; Polity Press: Cambridge, UK, 2005.

13. Giddens, A. Modernity and Self-Identity. Self and Society in the Late Modern Age; Polity Press: Cambridge, UK, 1991.

14. Morley, D. Home Territories: Media, Mobility and Identity; Routledge: London, UK; New York, NY, USA, 2000.

15. Lee, T. Schema theory and the role of socio-spatial schemata. In Psychological Theories for Environmental Issues; Bonnes, M., Lee, T., Bonaiuto, M., Eds.; Ashgate Publishing Limited: Aldershot, UK, 2003; pp. 27-61.

16. Myers, D. Social Psychology, 7th ed.; McGraw-Hill: New York, NY, USA, 2002.

17. Hauge, Å.L.; Kolstad, A. Dwelling as an Expression of Identity. A Comparative Study among Residents in High-Priced and Low-Priced Neighbourhoods in Norway. Housing Theory Soc. 2007, 24, 272-292. [CrossRef]

18. Robinson, J.W. Institution and Home: Architecture as Cultural Medium; Techne Press: Amsterdam, The Netherlands, 2006.

19. Norberg-Schulz, C. Existence, Space and Architecture; Praeger: New York, NY, USA, 1971.

20. Norberg-Schulz, C. Genius Loci: Toward a Phenomenology of Architecture; Rizzoli: New York, NY, USA, 1980.

21. Henny, C.; Kempen, E.; Ozaki, R. Experiences and Meanings of Dwellings. Housing Theory Soc. 2002, 19, $114-116$.

22. Lawrence, R. Housing, Dwellings and Homes: Design Theory, Research and Practice; John Wiley: Chichester, UK, 1987.

23. Clapham, D. Housing Pathways: A Post Modern Analytical Framework. Housing Theory Soc. 2002, 19, 57-68. [CrossRef]

24. Clapham, D. The Meaning of Housing, a Pathways Approach; The Policy Press: Bristol, UK, 2005.

25. Paadam, K. Constructing Residence as Home: Homeowners and Their Housing Histories; TPÜ Kirjastus: Tallinn, Estonia, 2003.

26. Jenkins, R. Social Identity, 3rd ed.; Routledge: Oxon, UK, 2008.

27. Speller, G. A Community in Transition: A Longitudinal Study of Place Attachment and Identity Process in the Context of an Enforced Relocation. Ph.D. Thesis, University of Surrey, Guildford, UK, 2000.

28. Tajfel, H. Social Identity and Intergroup Relations; Cambridge University Press: Cambridge, UK, 1982.

29. Breakwell, G.M. Threatened Identities; Wiley: Chichester, UK, 1983.

30. Gifford, R. Environmental Psychology: Principles and Practice, 3rd ed.; Optimal Books: Colville, WA, USA, 2002.

31. Stokols, D.; Shumaker, S.A. People in places: A transactional view of settings. In Cognition, Social Behavior and the Environment; Harvey, J.H., Ed.; Lawrence Erlbaum Associate Publishers: Hillsdale, NJ, USA, 1981; pp. 441-488.

32. Küller, R. Environmental assessment from a neuro-psychological perspective. In Environment, Cognition and Action: An Integrated Approach; Evans, T.G., Ed.; Oxford University Press: Oxford, UK, 1991; pp. 111-147.

33. Norberg-Schulz, C. Architecture. Presence, Language, Place; Skira: Milan, Italy, 2000.

34. Chaney, D. Lifestyles; Routledge: London, UK, 1996.

35. Danuta Niezabitowska, E. Research Methods and Techniques in Architecture; Routledge: New York, NY, USA, 2018.

36. Mugerauer, R. Interpreting Environments: Tradition, Deconstruction, Hermeneutics; University of Texas Press: Austin, TX, USA, 1995.

37. Miles, M.B.; Huberman, M. Qualitative Data Analysis: An expanded Sourcebook, 2nd ed.; Huberman, M., Ed.; Sage Publications: Thousand Oaks, CA, USA, 1994.

38. Mills, E. Social Identity in High-Density Housing. Fifth Year Architectural Thesis, School of Design North Carolina State University, Raleigh, NC, USA, 1966. 
39. Vershure, B.E.; Magel, S.; Sadalla, E. House Form and Social Identity. In The Behavioral Basis of Design; Dowden, Hutchinson \& Ross: Stroudsburg, PA, USA, 1976.

40. Canter, D. The Psychology of Place; The Architectural Press: London, UK, 1977.

41. Duncan, J.S. Housing and Identity: Cross-Cultural Perspectives; Croom Helm: London, UK, 1981.

42. Stedman, R.C. Toward a Social Psychology of Place: Predicting Behavior from Place-Based Cognitions, Attitude, and Identity. Environ. Behav. 2002, 34, 561-581. [CrossRef]

43. Manzo, L.C. Beyond House and Haven: Toward a Revisioning of Emotional Relationships with Places. J. Environ. Psychol. 2003, 23, 47-61. [CrossRef]

44. Casakin, H.; Bernardo, F. The Role of Place Identity in the Perception, Understanding, and Design of Built Environments; Bentham Science Publishers: Danvers, MA, USA, 2012.

45. Relph, E. Place and Placelessness; Pion Limited: London, UK, 1976.

46. Buttimer, A. Home, Reach, and a Sense of Place. In The Human Experience of Space and Place; Seamon, A., Buttimer, D., Eds.; Croom Helm: London, UK, 1980; pp. 166-187.

47. Proshansky, H.M. The City and Self-Identity. Environ. Behav. 1978, 10, 147-169. [CrossRef]

48. Proshansky, H.M.; Fabian, A.K.; Kaminoff, R. Place-Identity: Physical World Socialization of the Self. J. Environ. Psychol. 1983, 3, 57-83. [CrossRef]

49. Gram-Hanssen, K.; Bech-Danielsen, C. House, Home and Identity from a Consumption Perspective. Housing Theory Soc. 2004, 21, 17-26. [CrossRef]

50. Diamond, M.; Turnipseed, T.L. Community, Home and Identity; Ashgate Publishing Company: Farnham, UK, 2012.

51. Seamon, D.; Magerauer, R. Dwelling, Place and Environment: An Introduction. In Dwelling, Place and Environment: Towards a Phenomenology of Person and World; Seamon, D., Magerauer, R., Eds.; Springer: New York, NY, USA, 1985; pp. 1-12.

52. Korpela, K.M. Place-Identity as a Product of Environmental Self-Regulation. J. Environ. Psychol. 1989, 9, 241-256. [CrossRef]

53. Moore, J. Placing Home in Context. J. Environ. Psychol. 2000, 20, 207-217. [CrossRef]

54. Bernardo, F.; Palma, J.M. Place Change and Identity Processes. Medio Ambiente Comport. Hum. 2005, 6, 71-87.

55. Sadalla, E.K.; Vershure, B.; Burroughs, J. Identity Symbolism in Housing. Environ. Behav. 1987, 19, 569-587. [CrossRef]

56. Senan, Z. The House as an Expression of Identity: The Case of the Palestinian House. Forum 1993, 2, 3-10.

57. Hauge, Å.L. Housing and Identity: The Meaning of Housing in Communicating Identity and Its Influence on Self-Perception. Ph.D. Thesis, Norwegian University of Science and Technology Faculty of Architecture and Fine Art, Trondheim, Trøndelag, 2009.

58. Keith, J.; Malpas, J. Material Objects, Identity and the Home: Towards a Relational Housing Research Agenda. Housing Theory Soc. 2013, 30, 281-292. [CrossRef]

59. Lee, C.; Hummon, D.M. A Place to Call Home: Identification with Dwelling, Community, and Region. Sociol. Q. 1993, 34, 111-131.

60. Bernardo, F.; Palma-Oliveira, J. Place Identity, Place Attachment and the Scale of Place: The Impact of Place Salience. PsyEcology 2013, 4, 167-193. [CrossRef]

61. Lojanica, V.; Međo, V.; Ristić Trajković, J. Chronological review of multi-family housing architecture development in Belgrade. In Housing Development in Serbia in the Context of Globalization and Integrations. Approaches and Experiences; Mako, V., Lojanica, V., Božović Stamenović, R., Eds.; University of Belgrade Faculty of Architecture: Belgrade, Serbia, 2011; Volume 1, pp. $34-57$.

62. Lawrence, A.R.; Schafer, A. Re: Programming. PRAXIS J. Writ. Build. 2006, 8, 4-5.

63. Jabareen, Y.R. Sustainable Urban Forms: Their Typologies, Models, and Concepts. J. Plan. Educ. Res. 2006, 26, 38-52. [CrossRef]

64. Deleuze, G.; Guattari, F. A Thousand Plateaus; University of Minnesota Press: Minneapolis, MA, USA, 1987.

65. United Nations. Our common future: Report of the World Commission on Environment and Development; Oxford University Press: New York, NY, USA, 1987.

66. Ristić Trajković, J. Re:programiranje. Koncipiranje, interpretacija i transformacija stambenog plana. In Omnibus: Kratke Priče na Stambene teme; Lojanica, V., Dragišić, M., Eds.; Arhitektonski fakultet: Beograd, Serbia, 2018; pp. 140-175. 